SCIENTIFIC LETTER

\title{
Fibrinolytic treatment for recurrent left sided prosthetic valve thrombosis
}

\author{
R P Balasundaram, G Karthikeyan, S S Kothari, K K Talwar, P Venugopal
}

Heart 2005;91:821-822. doi: 10.1136/hrt.2004.044123

A bout $20-25 \%$ of patients develop recurrent thrombosis after successful thrombolysis for a first episode of prosthetic valve thrombosis (PVT). ${ }^{12}$ Whereas fibrinolytic treatment (FT) is an acceptable modality of treatment for a first episode of PVT, there are few data on patients with recurrent PVT. We compared the outcome of FT in patients with recurrent PVT with those treated for a first episode.

\section{METHODS}

From January 2000 to January 2003, 51 patients with 75 episodes of PVT were treated with FT. Of the 51 patients, 17 received treatment for a recurrent episode while the rest were treated for a first episode. Fifteen of the 17 patients treated for a recurrent episode had their first episode of PVT during the study period. In all, there were 26 episodes of recurrent PVT and 49 first episodes. Streptokinase was used in 59 episodes (46 first and three recurrent), and urokinase in 16 episodes (three first and 13 recurrent). Serial transthoracic echocardiography (TTE) and fluoroscopic assessment were used to guide treatment.

A protocol of prolonged fibrinolytic infusion was used. Streptokinase was given in a $250000 \mathrm{U}$ bolus over 30 minutes, followed by an infusion of $100000 \mathrm{U} / \mathrm{h}$. Urokinase was given in a dose of $4400 \mathrm{U} / \mathrm{kg}$ per hour as a continuous infusion. ${ }^{3}$ Throughout the duration of the infusion patients were closely monitored in an intensive care set up. Bedside TTE with Doppler imaging was carried out at the beginning of the infusion and at six hourly intervals. Leaflet mobility, the presence and extent of regurgitation, and transvalvar gradients were measured. The mean diastolic gradient (MDG) and end diastolic gradient (EDG) were measured for the mitral prostheses and the instantaneous peak to peak gradient (IPPG) for the aortic prosthesis. The mitral valve area was calculated by the pressure half time method. Cinefluoroscopy at 25 frames per second was carried out at the beginning of infusion and at 8-12 hourly intervals. The degree of restriction of disc movement and opening and closing angles were noted during each study. The indicators to terminate the infusion were: (1) improvement in clinical status accompanied by objective evidence of complete recovery on TTE and cinefluoroscopy; (2) occurrence of intracranial bleed or other major haemorrhage needing blood transfusion; (3) the elapsing of 72-96 hours even in the absence of a complete response. Patients were classified into four groups based on clinical presentation as described previously. ${ }^{3}$

The effect of FT was evaluated as haemodynamic and clinical end points. Complete haemodynamic response was defined as: (1) normalisation of transvalvar gradients on TTE $(\mathrm{MDG} \leqslant 6 \mathrm{~mm} \mathrm{Hg}, \mathrm{EDG} \leqslant 2 \mathrm{~mm} \mathrm{Hg}, \mathrm{IPPG} \leqslant 30 \mathrm{~mm} \mathrm{Hg}$ ), and (2) restoration of normal leaflet motion on cinefluoroscopy. Partial haemodynamic response was defined as: (1) reduction of transvalvar gradients by more than $50 \%$ from the baseline although the status before PVT was not reached; or (2) restricted movement of prosthetic valve leaflets on cinefluoroscopy even though the transvalvar gradients completely normalised. Haemodynamic failure was defined as a less than $50 \%$ decrease in the transvalvar gradients.

Complete clinical success was defined as complete haemodynamic response in the absence of any major complications. Partial clinical response was defined as either partial or complete haemodynamic response in the event of either major haemorrhagic or embolic complication (a major embolic complication was defined as one resulting in irreversible neurological damage, myocardial infarction, or needing limb salvage surgery). Clinical failure occurred in the event of haemodynamic failure or if a complication resulted in death irrespective of the haemodynamic response.

Categorical data were compared using the $\chi^{2}$ test. The paired $t$ test was used to compare continuous variables between the first and recurrent episodes of PVT. A probability value of $\mathrm{p}<0.05$ was considered significant.

Abbreviations: EDG, end diastolic gradient; $\mathrm{FT}$, fibrinolytic treatment; IPPG, instantaneous peak to peak gradient; $M D G$, mean diastolic gradient; PVT, prosthetic valve thrombosis; TTE, transthoracic echocardiography

Table 1 Comparison of the results of FT for first and recurrent episodes of PVT

\begin{tabular}{|c|c|c|c|c|c|c|}
\hline \multirow[b]{2}{*}{ Extent of response } & \multicolumn{3}{|c|}{ Haemodynamic } & \multicolumn{3}{|l|}{ Clinical } \\
\hline & $\begin{array}{l}\text { First } \\
\text { episode }\end{array}$ & $\begin{array}{l}\text { Recurrent } \\
\text { episodes }\end{array}$ & p Value & $\begin{array}{l}\text { First } \\
\text { episode }\end{array}$ & $\begin{array}{l}\text { Recurrent } \\
\text { episodes }\end{array}$ & p Value \\
\hline Complete & 36 (73.5) & $15(57.7)$ & 0.16 & $33(67.3)$ & $13(50)$ & 0.14 \\
\hline Partial & $7(14.3)$ & $5(19.2)$ & 0.82 & $10(20.4)$ & $7(26.9)$ & 0.72 \\
\hline Failure & $6(12.2)$ & $6(23.1)$ & 0.37 & $6(12.2)$ & $6(23.1)$ & 0.37 \\
\hline \multicolumn{7}{|l|}{ Clinical failure } \\
\hline Death & & & & $3(6.1)$ & $1(3.8)$ & 0.57 \\
\hline Stroke & & & & $3(6.1)$ & $6(23.1)$ & 0.04 \\
\hline Major bleed & & & & 0 & $1(3.8)$ & - \\
\hline Major complications and death & & & & $6(12.2)$ & $8(30.7)$ & 0.05 \\
\hline Minor bleed & & & & $2(4.1)$ & $1(3.8)$ & 0.725 \\
\hline
\end{tabular}




\section{RESULTS}

Demographic characteristics of patients presenting with a first PVT were similar to those with recurrent PVT. All episodes of recurrent PVT presented with haemodynamic symptoms (group 3), whereas group 1 (asymptomatic) or group 2 (systemic embolisation) symptom presentations were seen in $12 \%$ of patients during the first episode of PVT ( $p=0.02$ for difference). More patients with tilting disc prostheses had recurrent PVT $(23.5 \% \quad v \quad 14.7 \%$; $\mathrm{p}=$ not significant). There was no difference in the duration of fibrinolytic infusion between the first and recurrent episodes.

Both complete haemodynamic and complete clinical response occurred less often in patients with recurrent PVT than in those with first episodes. However, these differences were not significant. Stroke and a composite of death, stroke, or major bleeding occurred more often during treatment of recurrent PVT than during first episodes of PVT (table 1). Of the 33 patients who had a complete clinical response after treatment for a first episode of PVT, 15 (45.5\%) had a recurrence during the study period. Of the 17 patients with recurrent PVT, only six patients $(35.3 \%)$ remained free of further episodes at the end of the study period.

\section{DISCUSSION}

FT for a recurrent episode of PVT is not as efficacious as it is for the first episode and causes more adverse events. These patients have a greater tendency for repeated PVT after FT than when managed by thrombectomy $(8 \%)$ or valve replacement $(3 \%)$. It is possible that FT does not completely remove all of the thrombus from the valve, resulting in persistent abnormal flow patterns acting as a substrate for subsequent thromboses. Current methods of assessing restoration of valve function might not be sensitive enough to detect these minor residues. The accelerated formation of pannus on valves treated by FT may be another explanation for their predilection to recurrent PVT. This appears unlikely as most of our patients had short duration of symptoms before presentation (median 5 days, range 2-14 days) which did not differ from first episodes. Previous data suggest that duration of symptoms at presentation of less than one month favours thrombosis rather than pannus formation. ${ }^{4}$ Increased thrombus load in these predisposed valves might also explain the higher embolic stroke rate with FT in these patients.

In conclusion, recurrent episodes of PVT should probably be treated surgically.

\section{Authors' affiliations}

R P Balasundaram, G Karthikeyan, S S Kothari, K K Talwar, P Venugopal, All India Institute of Medical Sciences, New Delhi, India

Correspondence to: Dr Ganesan Karthikeyan, Room 22, Cardiothoracic Sciences Centre, All India Institute of Medical Sciences, Ansari Nagar, New Delhi, 110029, India; karthik_2010@hotmail.com

Accepted 26 October 2004

\section{REFERENCES}

1 Hering D, Piper C, Horstkotte D. Management of prosthetic valve thrombosis Eur Heart J 2001;3(suppl Q):Q22-6.

2 Gupta D, Kothari SS, Bahl VK, et al. Thrombolytic therapy for prosthetic valve thrombosis: short and long term results. Am Heart J 2000;140:906-16.

3 Lengyel $M$, Fuster $V$, Keltai $M$, et al. Guidelines for management of left-sided prosthetic valve thrombosis: a role for thrombolytic therapy. Consensus Conference on Prosthetic Valve Thrombosis. J Am Coll Cardiol 1997;30:1521-6.
4 Barbetseas J, Nagueh SF, Pitsavos C, et al. Differentiating thrombus from pannus formation in obstructed mechanical prosthetic valves: an evaluation of clinical, transthoracic and transesophageal echocardiographic parameters. J Am Coll Cardiol 1998;32:1410-7.

\section{WEB TOP 10}

www.heartinl.com

These articles scored the most hits on Heart's website during March 2005

1 Diagnosis and management of sudden cardiac death PS Spector

March 2005;91:408-13. (Education in Heart)

2 Transoesophageal echocardiography

PP Sengupta, BK Khandheria

April 2005;91:541-7. (Education in Heart)

3 Non-invasive multislice CT coronary imaging

NR Mollet, F Cademartiri, PJ de Feyter

March 2005;91:401-7. (Education in Heart)

4 Clinical significance of patent foramen ovale: introduction FA Flachskampf, WG Daniel

April 2005;91:437. (Mini-symposium)

5 Strain rate imaging after dynamic stress provides objective evidence of persistent regional myocardial dysfunction in ischaemic myocardium: regional stunning identified?

RI Williams, N Payne, T Phillips, J D'hooge, AG Fraser February 2005;91:152-60. (Cardiovascular medicine)

6 When and how to diagnose patent foramen ovale FJ Pinto

April 2005;91:438-40. (Mini-symposium)

7 Contemporary management of acute coronary syndromes: does the practice match the evidence? The global registry of acute coronary events (GRACE)

KF Carruthers, OH Dabbous, MD Flather, I Starkey, A Jacob, D MacLeod, KAA Fox, on behalf of the GRACE Investigators March 2005;91:290-8. (Cardiovascular medicine)

8 New insights into the pathology of inherited cardiomyopathy

SE Hughes, WJ McKenna

February 2005;91:257-64. (Education in Heart)

9 Stress echocardiography for the diagnosis and risk stratification of patients with suspected or known coronary artery disease: a critical appraisal

$R$ Senior, M Monaghan, $H$ Becher, J Mayet, $P$ Nihoyannopoulos

April 2005;91:427-36. (Review)

10 Investigation and management of chest pain

KF Fox

January 2005;91:105-10. (Education in Heart)

Visit the Heart website for hyperlinks to these articles, by clicking on "Top 10 papers"

www.heartinl.com 